\title{
PERCEIVED BARRIERS AND MOTIVATORS TO SMOKING CESSATION AMONG SOCIALLY-DISADVANTAGED POPULATIONS IN POLAND
}

\section{KATARZYNA MILCARZ ${ }^{1}$, KINGA POLAŃSKA ${ }^{1}$, ŁUKASZ BALWICKI ${ }^{2}$, TERESA MAKOWIEC-DĄBROWSKA ${ }^{3}$, WOJCIECH HANKE ${ }^{4}$, LEOKADIA BĄK-ROMANISZYN ${ }^{5}$, and DOROTA KALETA ${ }^{1}$}

\author{
${ }^{1}$ Medical University of Lodz, Łódź, Poland \\ Department of Hygiene and Epidemiology \\ ${ }^{2}$ Medical University of Gdansk, Gdańsk, Poland \\ Department of Public Health and Social Medicine \\ ${ }^{3}$ Nofer Institute of Occupational Medicine, Łódź, Poland \\ Department of Work Physiology and Ergonomics \\ ${ }^{4}$ Medical University of Lodz, Łódź, Poland \\ Department of Computer Science and Medical Statistics \\ ${ }^{5}$ Medical University of Lodz, Łódź, Poland \\ Department of Nutrition in Digestive Tract Diseases
}

\begin{abstract}
Objectives: This study aimed at assessment of the perceived barriers and motivators to smoking cessation among socially-disadvantaged populations in Poland. It is hypothesized that different factors can be considered depending on the level of smoking addiction. Therefore, a comparison between light and heavy smokers was performed. Material and Methods: Data collected during the second wave of a cross-sectional study carried out in the Piotrkowski District in October 2016 - February 2017 among 1668 socio-economically disadvantaged persons constituted the source of information for the present study. Barriers and motivators to smoking cessation among daily smokers were identified via face-to face interviews. Results: About one-third of the studied population admitted to being current daily smokers, almost $75 \%$ of whom were heavy smokers. The most common barriers to quitting smoking were related to difficulties in quitting (62\%), the lack of willingness to quit (56\%), as well as addiction and withdrawal symptoms (craving cigarettes [65\%], habit [56\%], stress and mood swings [55\%]). A significantly higher proportion of such barriers was noted among heavy smokers compared to light smokers $(\mathrm{p}<0.05)$. The following motivations to quit were pointed out by the respondents: available pharmacotherapy (47\%), access to a free-of-charge cessation clinic (40\%), and encouragement and support provided by their doctor (30\%), with no differences between various levels of smoking addiction ( $\mathrm{p}>0.05$ ). Conclusions: Developing effective interventions targeted at unique deprived populations requires understanding the barriers and motivators to quitting smoking. Social support and financial issues, including free-of-charge pharmacotherapy and cessation clinics, as well as doctor's encouragement and support, are crucial for successful smoking cessation in this vulnerable population. Int J Occup Med Environ Health. 2019;32(3):363-77
\end{abstract}

Key words:

tobacco, smoking cessation, cessation treatment effectiveness, barriers, motivators, tobacco control

Funding: this study was supported by Norway Grants, and co-financed by the Polish State budget (grant No. PL13-27/032/13/NMF/2015/00/2802/678 entitled "Your heart is your life - a program for reducing social inequalities in health," grant manager: Dorota Kaleta) and the Medical University of Lodz (grant No. 503/6-024-01/503-66-001). Received: July 25, 2018. Accepted: November 2, 2018.

Corresponding author: Dorota Kaleta, Medical University of Lodz, Department of Hygiene and Epidemiology, Żeligowskiego 7/9, 90-752 Łódź, Poland (e-mail: dorota.kaleta@umed.lodz.pl). 


\section{INTRODUCTION}

Harmful effects of smoking on physical health and wellbeing have been extensively discussed and documented throughout the world since the early 1960s [1-6]. Tobaccorelated diseases have led to $>5$ million deaths annually since 1990, with a steadily growing contribution to the overall disease burden, especially in lower income countries - in 2015 smoking was found to be the second key risk factor for early death and disability worldwide [7].

Extensive research has quantified the economic burden of smoking on the society with the help of avoidable healthcare expenditures and via indirect losses associated with morbidity and mortality [8]. Smoking-related diseases accounted for $5.7 \%$ of the global health expenditures in 2012, while the total economic cost of smoking (based on the combined healthcare expenditures and productivity losses) corresponded to $1.8 \%$ of the world's annual gross domestic product (GDP). The heavy economic burden that smoking imposes is seen most distinctly in Europe, where the cost of smoking-attributable diseases is equivalent to $2.5 \%$ of the region's annual GDP. There are, however, significant sub-regional variations, with Eastern Europe standing out with as much as 3.6\% of the GDP, compared to $2 \%$ for other European countries. The smoking-attributable death (SAD) rate in Poland, for instance, is estimated at 353, and the smoking-attributable fraction (SAF) at $6.6 \%$ of the combined health expenditures.

Regardless of the undisputed evidence on the harmful effects of tobacco, covering a period of over half a century, the worldwide age-standardized prevalence of daily smoking in 2015 amounted to 25\% (95\% uncertainty interval [UI]: 24.2-25.7) in men and 5.4\% (95\% UI: 5.1-5.7) in women [7]. Compared to the global average for men, a substantially higher smoking prevalence was found in 51 countries and territories, mostly located in Central and Eastern Europe. In the case of women, 70 countries, located primarily in Western and Central Europe, exceeded the global average significantly. The prevalence of daily smoking for men was the highest in countries with a medium socio-demographic index (SDI), as opposed to daily smoking women who stood out in high SDI countries. The quarter-century period between 1990 and 2015 demonstrated a visible decline in the global agestandardized prevalence of daily smoking for both sexes, dropping by $28.4 \%$ (95\% UI: $25.8-31.1$ ) for men and $34.4 \%$ (95\% UI: 29.4-38.6) for women. Nevertheless, smoking still remains a key public health concern. Interestingly, the rate of progress for smoking prevalence reduction has not been consistent across geographies, development status and sex, which indicates, as enunciated by the recent trends, that the drive to maintain the past rates of decline must not be considered obvious, especially among women and in low to middleSDI countries. This is further corroborated by the fact that the current process of smoking rate reduction in Europe has not been as expeditious as many expected; it is also notable that the degree of that progress is hugely diversified.

It cannot be stressed enough that smoking prevalence and related health risks are, in general, higher among sociallydisadvantaged groups, which translates into earlier smoking starts, the heaviness of smoking and less successful quit attempts, as compared to groups enjoying better life situations [9-13]. In recent years much research has explored motivators and barriers to quitting smoking among specific disadvantaged groups, including mental health patients, those living in socio-economically deprived areas, and pregnant Aboriginal and Torres Strait Islander women. The following barriers to quitting smoking have been considered: the lack of knowledge, poor self-efficacy, prosmoking community norms and the lack of willpower [1419]. It is hypothesized that financial stress and characteristics of smokers' social environments influence smoking cessation [20,21]. In addition, disadvantaged populations may have difficulty accessing healthcare and obtaining cessation advice, and thus fail to receive cessation treatment during a quit attempt. Skepticism about treatment effectiveness might also contribute to the insufficient administration of treatment and the lack of success [22]. 
In Poland, smoking rate declines have been seen over many decades, but as many as almost one-third (30.3\%) of the population still continue to be current (daily or occasional) smokers. Additionally, recent research has demonstrated that specific settings are conducive to a much higher smoking prevalence, with men from the socially-disadvantaged populations of social assistance clients being affected the most $(50 \%)$ [13]. Tobacco dependence is a chronic disease that often requires repeated interventions and multiple attempts to quit. However, for the purpose of developing tobacco control measures, understanding the perceived barriers and motivators to smoking cessation may increase the rates of long-term abstinence. Developing effective interventions for unique deprived populations requires comprehensive research to determine both the normative beliefs and perceived barriers to bringing about a change among the group to be targeted, and to ensure implementation of a culturally relevant and acceptable intervention [18]. Health behaviors are embedded within a social and cultural context, which is especially important to consider when attempting to address health disparities in vulnerable or marginalized groups [2327]. Unfortunately, currently there are no data available on the barriers and motivators to smoking cessation among the severely disadvantaged population of beneficiaries of the government welfare assistance in Poland.

This study aimed at assessment of the perceived barriers and motivators to smoking cessation among socially-disadvantaged populations in Poland. It is hypothesized that different factors can be considered depending on the level of smoking addiction. Therefore, a comparison between light and heavy smokers was performed.

\section{MATERIAL AND METHODS}

\section{Study design and population}

Data collected during the second wave of a cross-sectional study performed in the Piotrkowski District, which was part of the PL-13 Program "Reducing Social Inequalities in Health," supported by a grant from Norway through
Norway Grants and co-financed by the Polish state, constituted the source of information for the present study. Detailed characteristics of the district, program assumptions and methodology have all been published elsewhere $[13,28,29]$. The second wave of the study was conducted in order to collect data on the potential changes in respondents' lifestyles that may happen during the observed period, and to broaden the knowledge on some further factors that may influence selected health behaviors among the study participants, including smoking cessation. Thus, among others, issues related to the perceived barriers and motivators to smoking cessation were incorporated into the existing survey tool.

The second questionnaire survey was completed in October 2016 - February 2017. The investigation was based on a sample of socially-disadvantaged adults aged 18-59, residents of the Piotrkowski District, entitled to social aid from welfare institutions of the local government. Benefits under the system are granted to individuals and families who claim to live below a certain income threshold. Monetary benefits are discharged based on the monthly income per capita in any given household. For the purposes of the study and in line with the relevant local regulations, socio-economically disadvantaged (SD) persons are defined as those whose income threshold does not exceed 158 USD (634 PLN) per month for individuals, and 128 USD (514 PLN) per month for family members [30]. All those who met the inclusion criteria were invited to participate in the examination (3636 of the inhabitants). About $46 \%$ of the study population provided their responses, based on 1668 face-to-face interviews.

The project was approved by the Bioethics Committee of the Medical University in Lodz, Łódź, Poland (Project Identification Code: RNN/243/15/KE).

\section{Measurements}

Detailed information on the questionnaire and its contents is available in the previous research papers [13,28,29]. The adopted research tool, provided for the collection of in- 
formation on the respondents' socio-demographic status, included gender (male, female), age (years), education (primary, vocational, secondary, and higher education), employment status (currently employed with a permanent job, temporarily employed, retired, disability pensioners, students, currently without a permanent or part time job, or unemployed), subjective assessment of monthly income (sufficient to cover all living needs and able to save a certain amount, sufficient to cover all living needs, sufficient to cover the basic needs only, not sufficient to cover even the basic needs, response declined, don't know), subjective health state (fair, rather fair, neither fair nor poor, rather poor, poor), and respondents' declared health problems (none, 1-3, 4-6, > 7).

In addition, data on the tobacco smoking status and environmental tobacco smoke (ETS) exposure were collected. The current smokers category included daily smokers (smoking $\geq 1$ cigarettes per day over a past 30-day period at a minimum) and occasional smokers (those respondents who did not smoke on a daily basis). The nonsmoker category included never-smokers and ex-smokers. The current analysis was focused only on daily smokers. The participants were also asked about the type of cigarettes they smoked the most frequently and the number of cigarettes smoked per day. The daily smokers who smoked $<10$ cigarettes/day were considered light smokers and those smoking $\geq 10$ cigarettes/day were considered heavy smokers. An intention to quit smoking expressed by the study participants was organized in the following categories: intend to quit smoking within the next month, consider quitting smoking within the next 12 months, will quit smoking but not within the next 12 months, do not intend to quit smoking, or do not know/no decision.

Furthermore, the study participants were asked whether they had ever tried to quit (yes/no), as well as about the number of quit attempts and the time of the last attempt to quit smoking (within the last month, 1-6 months, 6-12 months, > 12 months prior to the study).
In an effort to assess the study population's awareness of the negative health consequences of active smoking, the following questions were brought up: "Does smoking tobacco cause serious illnesses?" The available answers included "yes," "no," and "don't know." The smokers were also requested to answer "yes" or "no" to several barriers and motivators to smoking cessation. A selection of potentially important factors for quitting and maintaining abstinence was based on the existing literature.

The following barriers were included: I do not want to quit; it is too difficult to quit; I do not know how to quit; poor knowledge about the available quit support; fear of weight gain; smoking for stress relief; I cannot afford medication; I cannot afford specialist medical service; the lack of support; craving cigarettes; being around other smokers; habit; stress/mood swings.

In addition, the following motivators were evaluated: saving money spent on tobacco products; affordable medication; a doctor who would provide support and encouragement; a nurse who would provide support and encouragement; social care worker's support; support and encouragement from friends and family; access to a toll-free quit line; access to a free-of-charge quit website; access to free-ofcharge cessation clinics; concerns about health problems; current complaints; medical recommendations; concerns about family health problems; smoke-free legislation.

\section{Statistical analysis}

The Statistica Windows XP version 10.0 (StatSoft Poland Inc., Tulusa, USA) software package was used to perform the statistical analysis. Means and standardized deviations, as well as numbers, percentages and $95 \%$ confidence intervals $(95 \% \mathrm{CI})$, were calculated. Statistical associations of particular characteristics categories in the analyzed subgroups of respondents were assessed using an extended Mantel-Haenszel $\chi^{2}$ test.

The perceived barriers and motivators to quitting, and the $\chi^{2}$ test of independence for the comparison between 
the light and heavy smokers, were presented. All $\mathrm{p}$ values were 2 -sided and $p<0.05$ was used to indicate statistical significance.

\section{RESULTS}

\section{Characteristics of the study population}

In total, 1668 respondents, including 1133 females and 535 males, participated in the second wave of the study (92\% of the population that participated in the first stage of the project). The socio-demographic characteristics of the study participants have been published previously $[14,29,30]$. Briefly, in the studied group most of the respondents were 30-49 years old, only 5.8\% had high education, $<30 \%$ had a permanent job, and $2.8 \%$ assessed their monthly income as sufficient to cover all living needs with a possibility to save some amount. Subjective health was rated by $36.3 \%$ of the respondents as fair. The majority of the respondents were aware of the fact that smoking may cause serious diseases (87.8\%), and a large number of them (64.9\%) also rejected being exposed to passive smoking.

\section{Smoking characteristic of the study sample}

About one-third of the sample admitted to being current daily smokers and $22.7 \%$ to being heavy smokers, with a meaningful difference between the surveyed women $(15 \%)$ and men (38.9\%), $\mathrm{p}<0.05$ (Table 1). More women were occasional smokers $(6.2 \%$ vs. $2.2 \%, \mathrm{p}<0.05)$. The mean age of the smoking onset was higher among the women than among the men $(19.3 \pm 3.7$ vs. $18.2 \pm 3, p<0.001)$.

\section{The level of smoking addiction}

\section{(a light vs. heavy smoking status)}

Table 1 presents characteristics depending on the level of smoking addiction. Most of the current daily smokers in the study group were heavy smokers $(74.1 \%)$. The heavy smokers were significantly older than the light smokers $(\mathrm{p}<0.006)$. They represented $82 \%$ of the daily smoking men and $67 \%$ of the daily smoking women $(\mathrm{p}<0.001)$. Among less educated people, the percentage of heavy smokers was significantly higher as compared to those with secondary or higher education $(\mathrm{p}<0.04)$. In the group of participants that declared smoking hand-rolled cigarettes, 92\% were heavy smokers, whereas among those who smoked slim cigarettes there were $35 \%$ of heavy smokers $(p<0.001)$. The percentage of heavy smokers was lower among the respondents who indicated previous quit attempts, compared to those who had not tried to quit smoking $(\mathrm{p}<0.04)$. Both the light and heavy smokers had tried to quit smoking on average 3 times ( $p>0.05$ ). However, the percentage of heavy smokers was higher among those who did not want to quit or wanted to do it but not in the near future ( $>70 \%$ ) than among those who declared an intention to quit within the following month $(56 \%, \mathrm{p}<0.005)$.

\section{Perceived barriers to quitting by smoking level (light vs. heavy smokers)}

The most important barriers to quitting smoking that the respondents indicated were: craving cigarettes $(64.7 \%$, including $50 \%$ of the light smokers, $69.8 \%$ of the heavy smokers; $p<0.05$ ); believing that quitting is too difficult $(61.6 \%$, including $31.8 \%$ of the light smokers, $72 \%$ of the heavy smokers; $\mathrm{p}<0.05$ ); the lack of willingness to quit (55.5\%, including $42.4 \%$ of the light smokers and $60.1 \%$ of the heavy smokers; $\mathrm{p}<0.05)$; habit $(56.3 \%$, including $31.8 \%$ of the light smokers, $64.8 \%$ of the heavy smokers; $\mathrm{p}<0.05)$; stress and mood swings $(54.5 \%$, including $43.2 \%$ of the light smokers, $58.5 \%$ of the heavy smokers; $\mathrm{p}<0.05$ ) (Table 2).

\section{Perceived motivators to quitting by smoking level (light vs. heavy smokers)}

Table 3 presents the motivators to smoking cessation that the light and heavy smokers perceived. Generally, a high proportion of the smokers pointed out available pharma- 


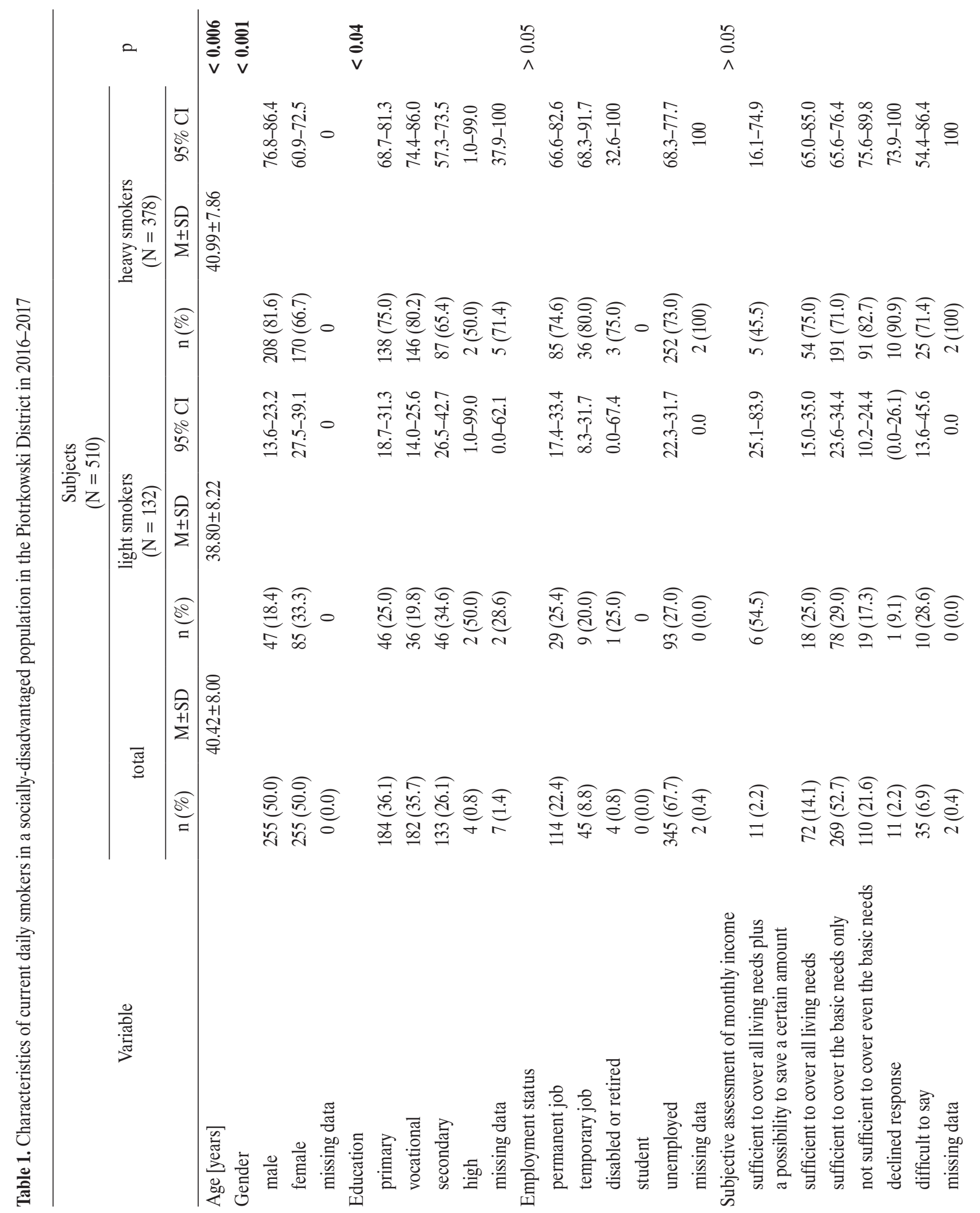


bे
$\ddot{0}$
$\wedge$

20
$\stackrel{0}{0}$
1

$\begin{array}{ll}2 & 2 \\ 0 & \stackrel{0}{0} \\ 1 & \wedge\end{array}$

$\underset{\mathrm{\delta}}{\mathrm{O}}$

$\begin{array}{lll}2 & \bar{\sigma} \\ \stackrel{0}{0} & \stackrel{0}{0} \\ \wedge & v\end{array}$

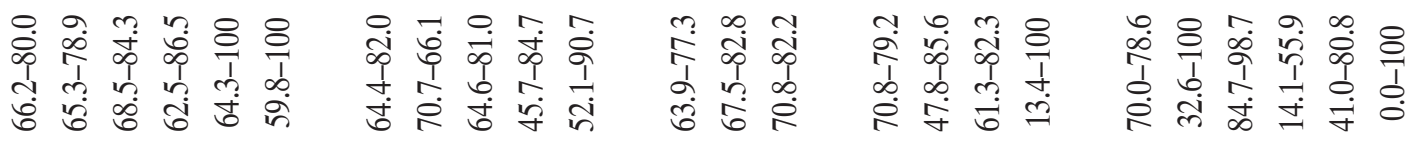

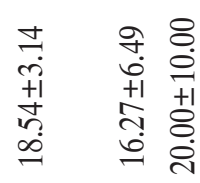

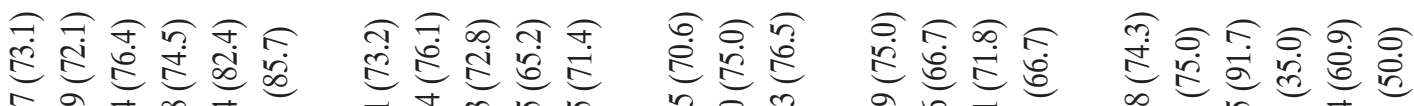

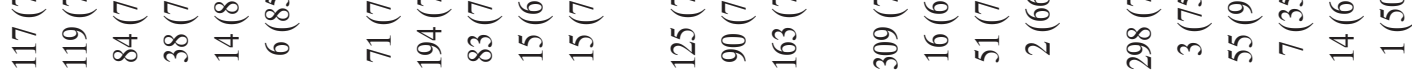

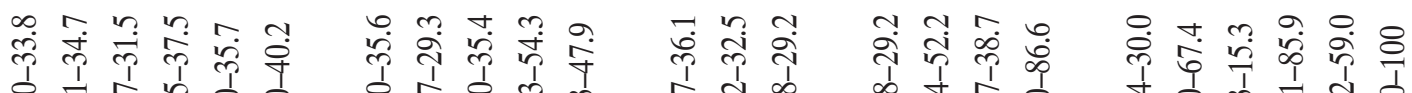

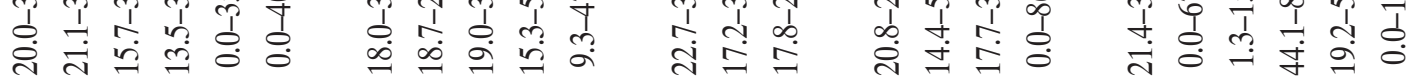

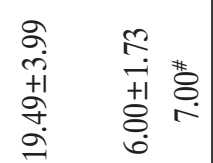

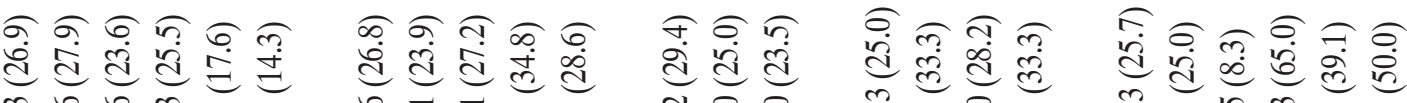

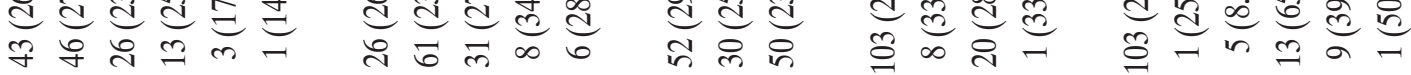

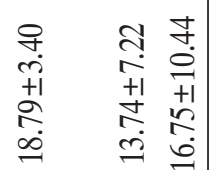

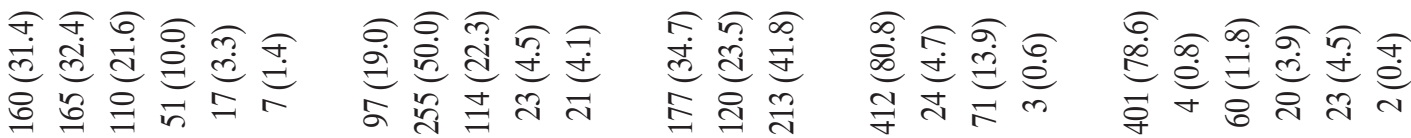

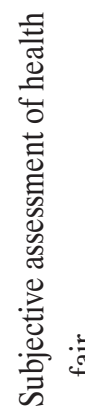

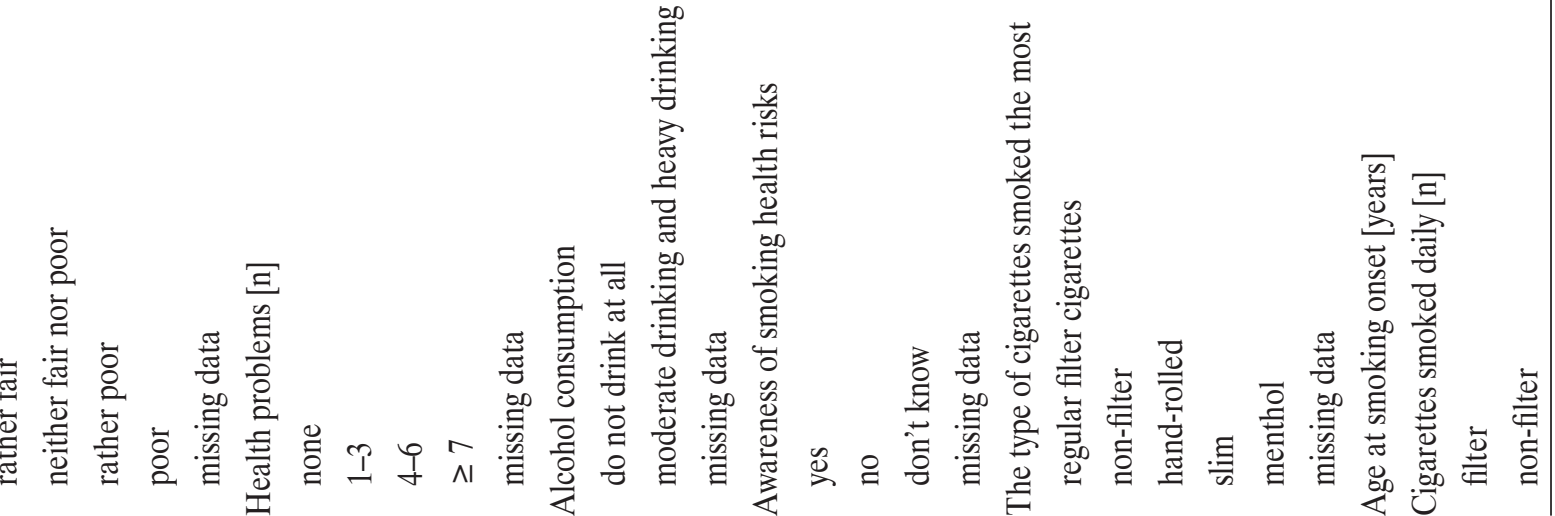




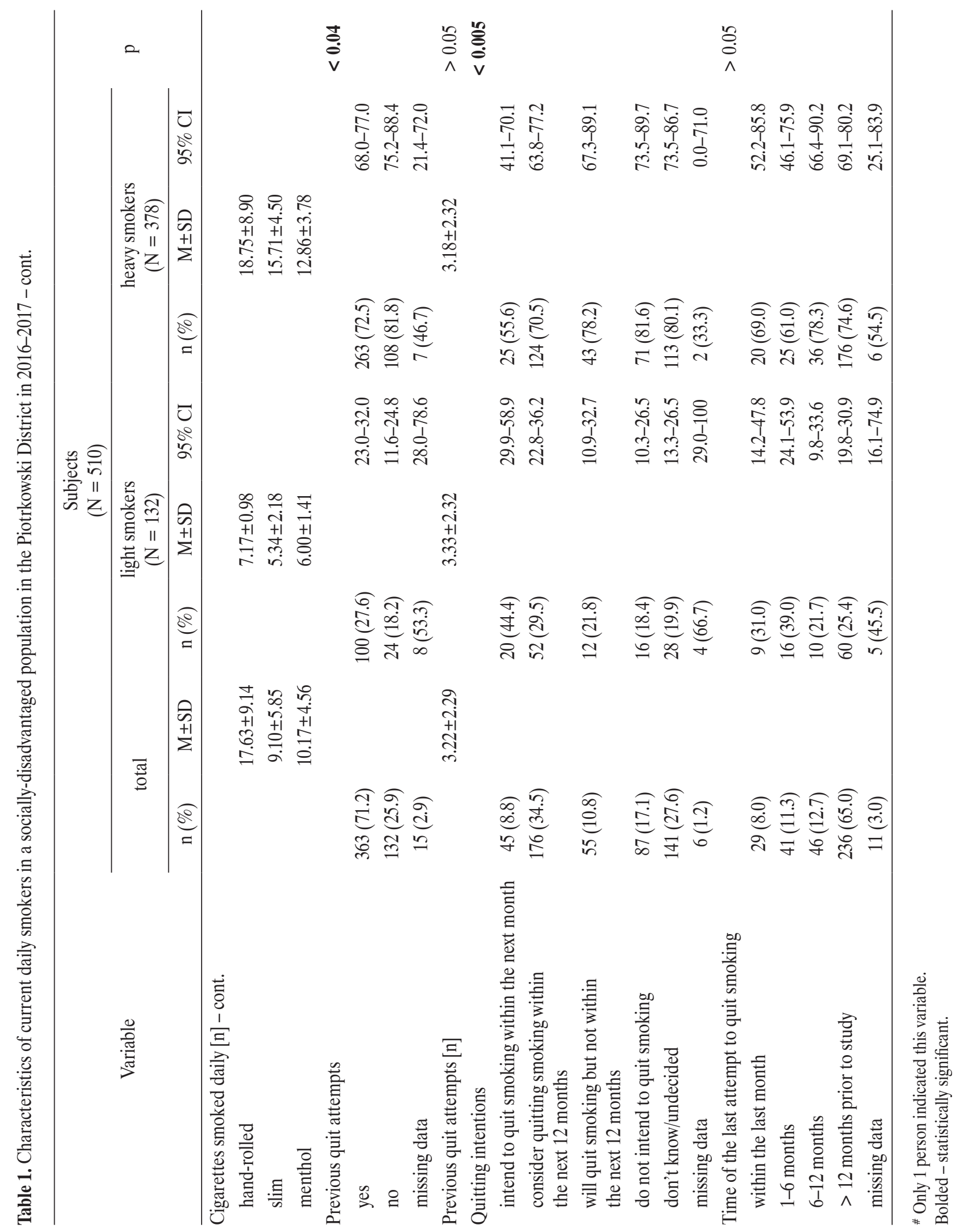




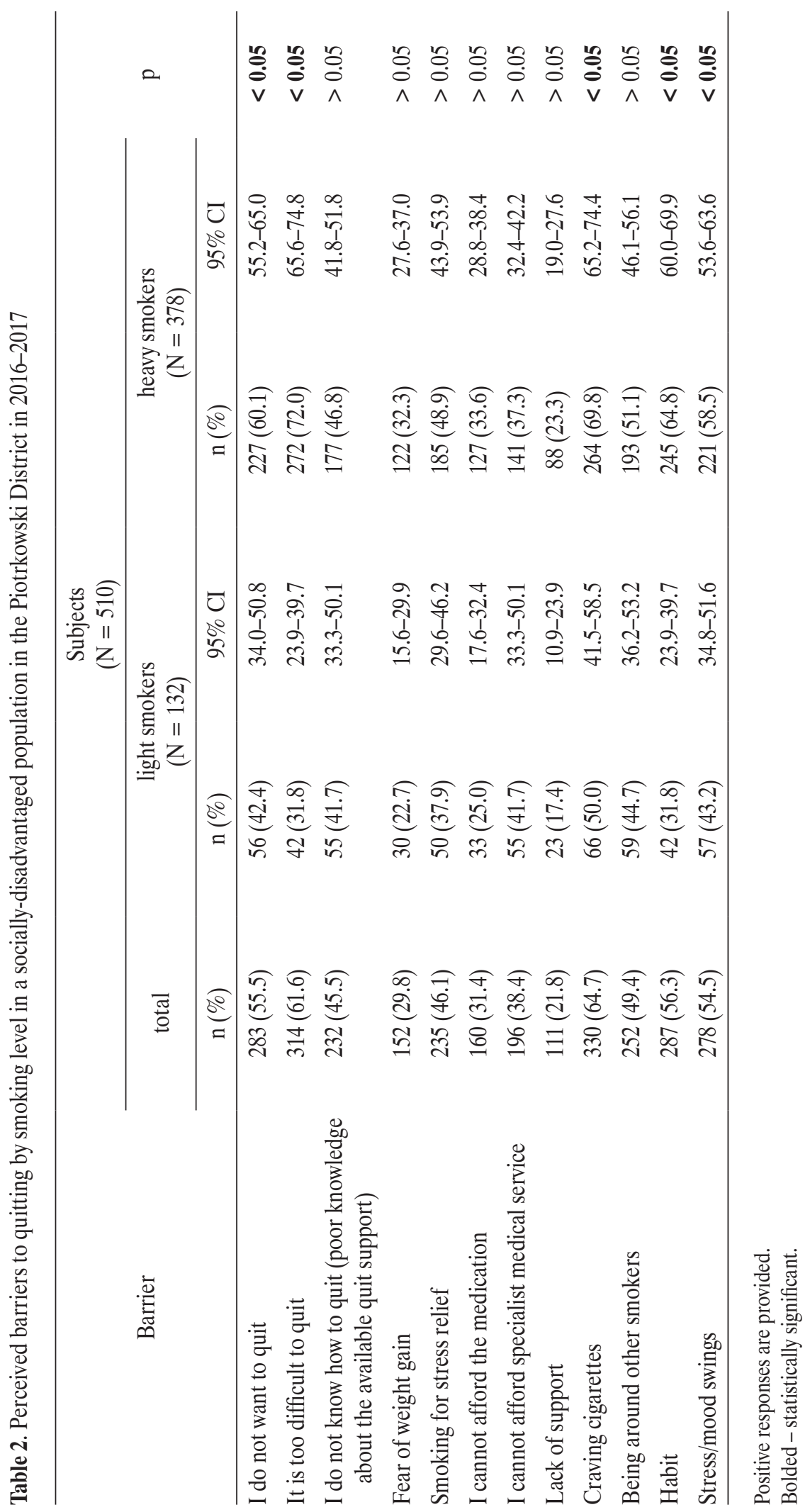




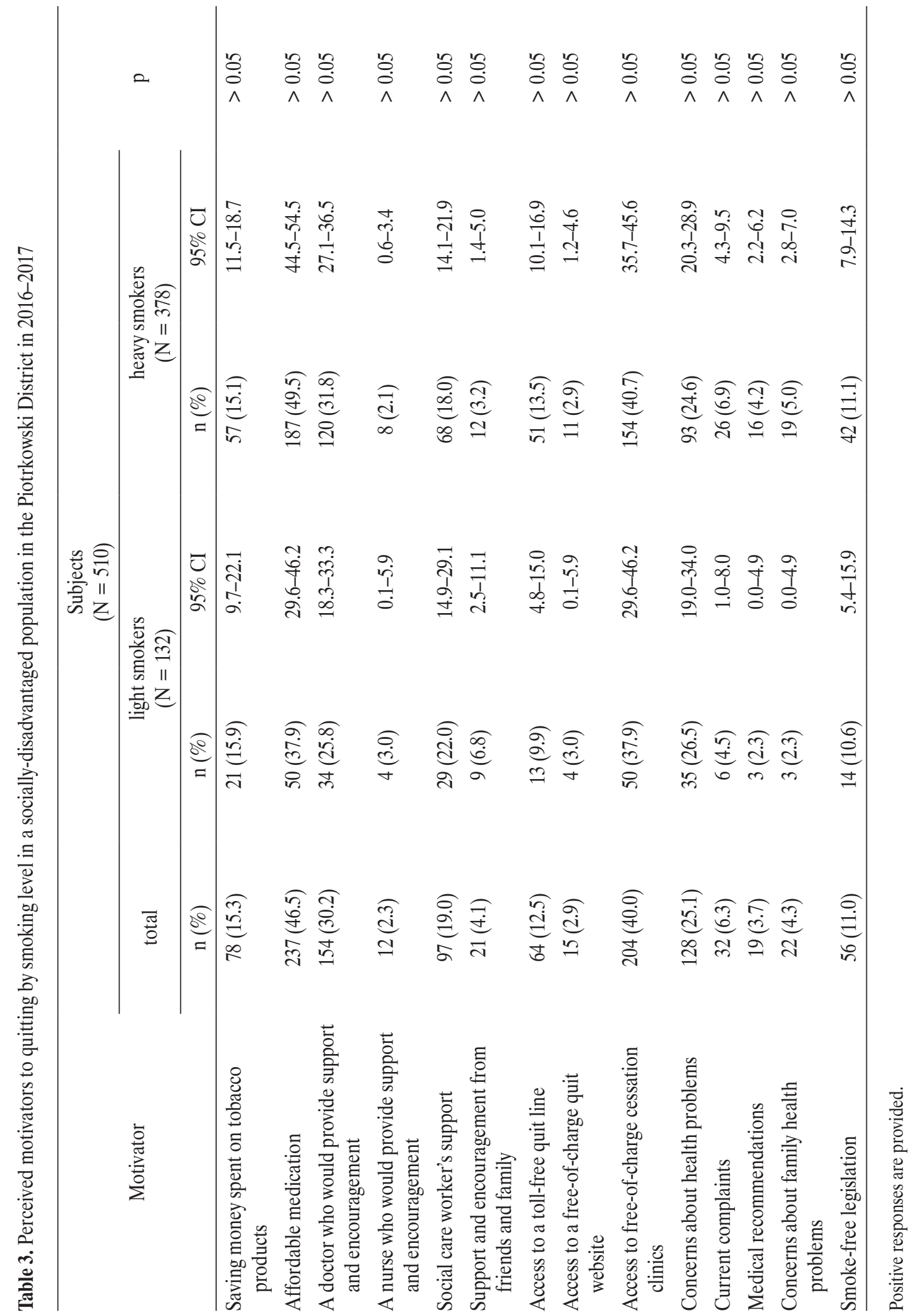


cotherapy (46.5\%), access to a free-of-charge cessation clinic (40\%), and a doctor who would provide support and encouragement $(30.2 \%)$. There were no statistically significant differences in the perceived motivators to quitting between the light and heavy smokers ( $p>0.05)$.

\section{DISCUSSION}

About one-third of the socially-disadvantaged population involved in the study admitted to being current daily smokers. What is more, a high proportion of them were heavy smokers, which means that they declared smoking $\geq 10$ cigarettes/day. The most common barriers to quitting were related to difficulties in quitting, the lack of willingness to quit, as well as addiction and withdrawal symptoms (craving cigarettes, habit, stress and mood swings). A significantly higher proportion of such barriers was noted among the heavy smokers than among the light smokers. A high proportion of smokers mentioned the following motivators to quitting: available pharmacotherapy, access to a free-of-charge cessation clinic, and a doctor who would provide encouragement and support. Understanding such barriers and motivators to smoking cessation is crucial for developing effective interventions for that unique deprived population.

A high prevalence of daily smokers (30.6\%), with a high proportion of heavily addicted people among them (74.1\%), suggests that disadvantaged conditions in which people live lead to a poorer health status. Data from the Global Adult Tobacco Survey (GATS, 2009-2010) that was performed on a representative sample of adults aged $\geq 15$ years has shown lower percentages of current daily smokers $(27 \%)$ than the percentages observed in the study population [31]. The differences are even more pronounced when looking at gender differences (the current daily smoking women in the study population: $22.5 \%$ vs. GATS: $21 \%$; the current daily smoking men in the study population: $47.7 \%$ vs. GATS: $33.5 \%$ ). In other countries, the proportion of smokers among social aid beneficiaries or socially-disadvantaged people is also higher than that reported for the general population [32-38]. These findings should encourage political leaders to fight down the existing socio-economic inequalities.

The smokers included in this sample admitted they had tried to quit smoking on average 3 times. Similar results were obtained in a study conducted in the USA, where respondents were asked how many times in their lifetime they had tried to quit smoking, and the average result was 2.9 , with more than a third, i.e., $37.7 \%$, replying "never" (this percentage is even higher than that observed in the study population) [39]. Such results should encourage health system managers to offer tailored services to the disadvantaged groups.

When it comes to the perceived barriers, the strength of dependence expressed in craving for cigarettes, habit, stress and mood swings, as well as belief that quitting smoking is too difficult emerged as the most important in this study. The study participants expressed a strong preference for free-of-charge pharmacotherapy and cessation clinics, as well as personalized quitting support. A recent review of the perceived barriers to smoking cessation in selected vulnerable groups by Twyman et al. [14] has described several groups of factors influencing cessation covering:

- individual and lifestyle issues (physical addiction, low confidence, behavioral habit, low motivation, failed past attempts, relaxation, stress and mood management, perceived mental health benefits, enjoyment, low health related knowledge, etc.),

- social and community barriers (the lack of support from a health professional, socializing, the lack of social support, high prevalence and acceptability of smoking in a community),

- living and working conditions (living and working circumstances, stressful situations, a limited structure in a day-to-day life, boredom, social and geographical isolation, access to resources to quit), 
- cultural, socio-economic and environmental factors (cultural norms, maintaining identity and socio-economic factors).

Also, a few other studies worldwide have determined similar factors that may increase quitting success in both the general and vulnerable populations [15-17].

The study by Hiscock et al. has indicated that affluent smokers who paid for prescriptions were more likely to quit than disadvantaged smokers eligible for free prescriptions [40]. The study has provided further evidence that disadvantaged smokers find quitting more difficult even when they attend a smoking cessation program. Surprisingly, Kotz and West have indicated that smokers from more deprived socio-economic groups are just as likely to try to stop smoking and use aids to cessation as those in higher groups, but there is a strong gradient across socio-economic groups in success, with those in the lowest group being half as likely to succeed compared to those from the highest group [41]. Other researchers also conclude their results with a statement, "Rather than quitting smoking, disadvantaged smokers quit treatment" [42]. In Poland, there is very limited access to smoking cessation counseling. Although pharmacotherapy is available on the market, none of the drugs is subsidized to make them more affordable to this group. Apart from that, there are no campaigns informing on the possibility of being offered help from health care professionals, beside information on the quit line placed on the packs of cigarettes. This stays in contrast with the WHO Framework Convention on Tobacco Control (FCTC) provisions as well as smoking cessation recommendations [43].

One must be aware of the fact that disadvantaged people are a more vulnerable group, and their views on smoking involve contradictions between feeling that smoking cessation involves personal responsibility, while at the same time feeling trapped by stressful life circumstances. These perceptions should be properly addressed in attempting to offer them effective interventions. The authors' results in this field are supported by other research, which suggests that smokers from these deprived areas generally have low awareness of the services available to help them, and misconceptions about their availability and effectiveness.

It needs to be pointed out that a more personalized approach to promoting services that are non-judgmental, coupled with free-of-charge pharmacotherapy and flexible support, may encourage more deprived smokers to quit smoking $[15,21]$. Free provision or reimbursement for the medications and nicotine replacement products increases quit attempts and abstinence [15]. It is easily understandable that social support is important for everyone who wants to quit, but for individuals in the neighborhood contexts of high smoking rates, social support for quitting may be particularly lacking [15]. Interventions aimed at changing community norms and programs that increase social support from health care providers, friends and family could be effective and fill that need [15].

The strengths of the study need to be pointed out. For the first time, information about the perceived barriers and motivators to smoking cessation have been collected from social care beneficiaries from a rural district in Poland. That information is crucial for interventions and cessation programs among this socially disadvantaged population. In addition, the interviewer-administered questionnaires completed during face-to-face interviews produced higher values of sensitivity and specificity than self-administered questionnaires, and helped to reduce the non-response rate. It also needs to be noted that from all those invited to participate in the study, about half agreed to take part in the survey (the participation rate is comparable to that obtained in other surveys in Poland (GATS Poland: 60\% [31], WOBASZ II: 45\% [44]). This study was subject to certain limitations. First, there was no objective validation of tobacco cigarette use, such as exhaled $\mathrm{CO}$ or measurements of cotinine. Also, its results cannot be generalized to the whole Polish population of disadvantaged citizens, as the authors only researched one region in Poland. These data were based on self-reports, which may be prone to response 
bias. However, the likelihood of the response bias was assumed to be minimal since the survey was conducted so that the respondents remained anonymous.

\section{CONCLUSIONS}

Developing effective interventions for unique deprived populations requires understanding the barriers and motivators to quitting smoking. Social support and financial issues, including free-of-charge pharmacotherapy and cessation clinics, as well as doctoral encouragement and support, are crucial for successful smoking cessation among this vulnerable population.

\section{REFERENCES}

1. Schroeder SA, Koh HK. Tobacco control 50 years after the 1964 surgeon general's report. JAMA. 2014;311(2):141-3, https://doi.org/10.1001/jama.2013.285243.

2. World Health Organization. WHO Global Report: Mortality attributable to tobacco. Geneva: The Organization; 2012.

3. U.S. Department of Health and Human Services. The health consequences of involuntary exposure to tobacco smoke: A Report of the Surgeon General. Atlanta: The Department; 2006.

4. U.S. Department of Health and Human Services. How tobacco smoke causes disease: The biology and behavioral basis for smoking-attributable disease: A report of the Surgeon General. Rockville: Department of Health and Human Services, Public Health Service, Office of Surgeon General; 2010.

5. Oberg M, Jaakkola, MS, Woodward A, Peruga A, Pruss-Ustun A. Worldwide burden of disease from exposure to secondhand smoke: A retropective analysis of data from 192 countries. Lancet. 2011;377(9760):139-46, https://doi.org/10.1016/ S0140-6736(10)61388-8.

6. Lv X, Sun J, Bi Y, Xu M, Lu J, Zhao L, et al. Risk of all-cause mortality and cardiovascular disease associated with secondhand smoke exposure: A systematic review and meta-analysis. Int J Cardiol. 2015;199:106-15, https://doi.org/10.1016/j.ijcard. 2015.07.011.
7. GBD 2015 Tobacco Collaborators. Smoking prevalence and attributable disease burden in 195 countries and territories, 1990-2015: A systematic analysis from the Global Burden of Disease Study 2015. Lancet. 2017;389(10082):18851906, http://dx.doi.org/10.1016/S0140-6736(17)30819-X.

8. Goodchild M, Nargis N, Tursan d'Espaignet E. Global economic cost of smoking-attributable diseases. Tob Control. 2018;27(1):58-64, https://doi.org/10.1136/tobaccocontrol-2016-053305.

9. World Health Organization. Tobacco and inequalities. In guidance for addressing inequities in tobacco-related harm. Geneva: The Organization; 2014.

10. Hiscock R, Bauld L, Amos A, Platt S. Smoking and socioeconomic status in England: The rise of the never smoker and the disadvantaged smoker. J Public Health. 2012;34(3):3906, https://doi.org/10.1093/pubmed/fds012.

11. Bryant J, Bonevski B, Paul C. A survey of smoking prevalence and interest in quitting among social and community service organisation clients in Australia: A unique opportunity for reaching the disadvantaged. BMC Public Health. 2011;11:827, https://doi.org/10.1186/1471-2458-11-827.

12. Cavelaars AE, Kunst AE, Geurts JJ, Crialesi R, Grötvedt L, Helmert U, et al. Educational differences in smoking: International comparison. BMJ. 2000;320(7242):1102-7, https:// doi.org/10.1136/bmj.320.7242.1102.

13. Milcarz K, Makowiec-Dąbrowska T, Bak-Romaniszyn L, Kaleta D. Smoking patterns and smoking cessation willingness A study among beneficiaries of government welfare assistance in Poland. Int J Environ Res Public Health. 2017;14(2): 131, https://doi.org/10.3390/ijerph14020131.

14. Twyman L, Bonevski B, Paul C, Bryant J. Perceived barriers to smoking cessation in selected vulnerable groups: A systematic review of the qualitative and quantitative literature. BMJ Open. 2014;4(12):e006414, https://doi.org/10.1136/bmjopen-2014-006414.

15. Rosenthal L, Carroll-Scott A, Earnshaw VA, Sackey N, O'Malley SS, Santilli A, et al. Targeting cessation: Understanding barriers and motivations to quitting among urban 
adult daily tobacco smokers. Addict Behav. 2013;38(3):163942, https://doi.org/10.1016/j.addbeh.2012.09.016.

16. Baig M, Bakarman MA, Gazzaz ZJ, Khabaz MN, Ahmed TJ, Qureshi IA, et al. Reasons and motivations for cigarette smoking and barriers against quitting among a sample of young people in Jeddah, Saudi Arabia. Asian Pac J Cancer Prev. 2016;17(7):3483-7.

17. Sieminska A, Buczkowski K, Jassem E, Lewandowska K, Ucinska R, Chelminska M. Patterns of motivations and ways of quitting smoking among Polish smokers: A questionnaire study. BMC Public Health. 2008;8:274, https://doi. org/10.1186/1471-2458-8-274.

18. Bryant J, Bonevski B, Paul C, O’Brien J, Oakes W. Developing cessation interventions for the social and community service setting: A qualitative study of barriers to quitting among disadvantaged Australian smokers. BMC Public Health. 2011;11:493, https://doi.org/10.1186/1471-2458-11-493.

19. Browning KK, Ferketich AK, Salsberry PJ, Wewers ME. Socioeconomic disparity in provider-delivered assistance to quit smoking. Nicotine Tob Res. 2008;10(1):55-61, https:// doi.org/10.1080/14622200701704905.

20. Guillaumier A, Twyman L, Paul C, Siahpush M, Palazzi K, Bonevski B. Financial stress and smoking within a large sample of socially disadvantaged Australians. Int J Environ Res Public Health. 2017;14(3):E231, https://doi.org/10.3390/ ijerph14030231.

21. Siahpush M, Yong HH, Borland R, Reid JL, Hammond D. Smokers with financial stress are more likely to want to quit but less likely to try or succeed: Findings from the International Tobacco Control (ITC) Four Country Survey. Addiction. 2009;104(8): 1382-90, https://doi.org/10.1111/j.1360-0443.2009.02599.x.

22. Hammett PJ, Fu SS, Burgess DJ, Nelson D, Clothier B, Saul JE, et al. Treatment barriers among younger and older socioeconomically disadvantaged smokers. Am J Manag Care. 2017;23(9):295-302.

23. Marmor TRR, Barer ML, Evans RG. Why are some people healthy and others not? The determinants of health of populations. New York: Walter De Gruyter; 1994.
24. Sullivan-Bolyai S, Bova C, Harper D. Developing and refining interventions in persons with health disparities: The use of qualitative description. Nurs Outlook. 2005;53(3):127-33, https://doi.org/10.1016/j.outlook.2005.03.005.

25. Tsourtos G, Ward PR, Muller R, Lawn S, Winefield AH, Hersh D, et al. The importance of resilience and stress to maintaining smoking abstinence and cessation: A qualitative study in Australia with people diagnosed with depression. Health Soc Care Community. 2011;19(3):299-306, https:// doi.org/10.1111/j.1365-2524.2010.00973.x.

26. Ward PR, Muller R, Tsourtos G, Hersh D, Lawn S, Winefield $\mathrm{AH}$, et al. Additive and subtractive resilience strategies as enablers of biographical reinvention: A qualitative study of ex-smokers and never-smokers. Soc Sci Med. 2011;72(7): 1140-8, https://doi.org/10.1016/j.socscimed.2011.01.023.

27. Tsourtos G, Ward PR, Muller R. Smoking and stress: The double-edged sword of living in a disadvantaged area. Australas Med J. 2008;1(1), https://doi.org/10.4066/amj.2008.8.

28. Milcarz K, Bak-Romaniszyn L, Kaleta D. Environmental tobacco smoke exposure and smoke-free rules in homes among socially-disadvantaged populations in Poland. Int J Environ Res Public Health. 2017;14(4):447, http://doi.org/ 10.3390/ijerph14040447.

29. Milcarz M, Polańska K, Bak-Romaniszyn L, Kaleta D. How social care beneficiaries in Poland rate relative harmfulness of various tobacco and nicotine-containing products. Int J Environ Res Public Health. 2017;14(9):1029, http://doi. org/10.3390/ijerph14091029.

30. [Assessment of Health Needs of the Residents of Piotrkowski District] [Internet]. Piotrków Trybunalski: Powiat Piotrkowski; 2014 [cited 2018 July 1]. Available from: http://www.zdrowie. powiat-piotrkowski.pl/download/Download/Ocena_potrzeb_ zdrowotnych_powiat_piotrkowski.pdf. Polish.

31. The Maria Skłodowska-Curie Cancer Center and Institute of Oncology, Medical University of Warsaw, Centers for Disease Control and Prevention. Global Adult Tobacco Survey Poland 2009-2010 [Internet]. Warsaw: Ministry of Health; 2010 [cited 2018 July 23]. Available from: http://www. 
who.int/tobacco/surveillance/en_tfi_gats_poland_report_ 2010.pdf.

32. Siahpush M, Borland R, Scollo M. Health inequalities: Prevalence and socio-economic correlates of smoking among lone mothers in Australia. Aust N Z J Public Health. 2002;26(2):132-5, https://doi.org/10.1111/j.1467-842X. 2002.tb00905.x.

33. Johnson TP, Barrett ME. Substance use and treatment needs among homeless persons in Cook County Illinois. Int J Addict. 1995;30(5):557-85.

34. Connor SE, Cook RL, Herbert MI, Neal SM, Williams JT. Smoking cessation in a homeless population: There is a will, but is there a way? J Gen Intern Med. 2002;17(2):369-72.

35. De Leon J, Diaz FJ. A meta-analysis of worldwide studies demonstrates an association between schizophrenia and tobacco smoking behaviors. Schizophr Res.2005;76(2-3):13557, https://doi.org/10.1016/j.schres.2005.02.010.

36. Lasser K, Boyd JW, Woolhandler S, Himmelstein DU, McCormick D, Bor DH. Smoking and mental illness: A population-based prevalence study. JAMA. 2000;284(20):2606-10, https://doi.org/10.1001/jama.284.20.2606.

37. Baggett TP, Rigotti NA. Cigarette smoking and advice to quit in a national sample of homeless adults. Am J Prev Med. 2010;39(2):164-72, http://doi.org/10.1016/j.amepre. 2010.03.024.

38. Kermode M, Crofts N, Miller P, Speed B, Streeton J. Health indicators and risks among people experiencing homelessness in Melbourne, 1995-1996. Aust N Z J Public Health.
1998;22(4):464-70, https://doi.org/10.1111/j.1467-842X.1998. tb01415.x.

39. Christiansen B, Reeder K, Hill M, Baker TB, Fiore MC. Barriers to effective tobacco-dependence treatment for the very poor. J Stud Alcohol Drugs. 2012;73(6):874-84, http:// doi.org/10.15288/jsad.2012.73.874.

40. Hiscock R, Murray S, Brose LS, McEwen A, Bee JL, Dobbie F, et al. Behavioural therapy for smoking cessation: The effectiveness of different intervention types for disadvantaged and affluent smokers. Addict Behav. 2013;38(11):2787-96, http://doi.org/10.1016/j.addbeh.2013.07.010.

41. Kotz D, West R. Explaining the social gradient in smoking cessation: It's not in the trying, but in the succeeding. Tob Control. 2009;18(1):43-6, http://doi.org/10.1136/tc.2008.025981.

42. Hiscock R, Judge K, Bauld L. Social inequalities in quitting smoking: What factors mediate the relationship between socioeconomic position and smoking cessation? J Public Health (Oxf). 2011;33(1):39-47, http://doi.org/10.1093/ pubmed/fdq097.

43. Tobacco Use and Dependence Guideline Panel. Treating tobacco use and dependence: 2008 Update. Clinical Practice Guidelines. Rokville: U.S. Department of Health and Human Services, Public Health Service; 2008.

44. Drygas W, Niklas A, Piwonska A, Piotrowski W, Flotynska A, Kwasniewska M, et al. Multi-centre National Population Health Examination Survey (WOBASZ II study): Assumptions, methods, and implementation. Pol Heart J. 2016;74(7):681-90.

This work is available in Open Access model and licensed under a Creative Commons Attribution-NonCommercial 3.0 Poland License - http://creativecommons.org/ licenses/by-nc/3.0/pl/deed.en. 